\title{
THE ORGANIZATION AND MANAGEMENT OF
}

\section{THE NOR:EEGIAN SOCIAL SCIENCE DATA SERVICES (NSD)}

\author{
JARLE BROSVEET, BJØRN HENRICHSEN, LARS W. HOLM, AND TERJE SANDE \\ NORWEGIAN SOCIAL SCIENCE DATA SERVICES \\ BERGEN, NORWAY
}

(This poper was de livered at the 1981 IFDO/IASSIST Conference, Grenoble.)

THE EARLY YEARS

The origins of the Norwegian Social Science Data Services (NSD) go back to 1967 when the Norwegian Research Council could no longer ignore various complaints about, long delays and frequent errors in the processing

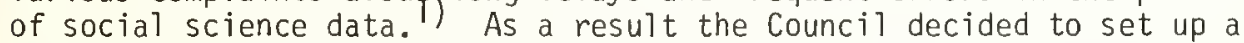
committee to study the reasons why bottlenecks occurred in computing services at the universities. The committee was also instructed to make proposals for improvement of social science computer facilities and services.

The committee made a number of recommendations and took the first steps to implement these as part of its work. A series of intensive courses in computing for social scientists was organized, a variety of statistical packages and specialized programs were acquired and installed on the university computers, and steps were taken to build up a first set of data banks easily accessible to researchers at all universities.

In 1970, the committee proposed to institutionalize these activities by establishing a nation-wide organization supplying various types of services to all social scientists. The Research Council approved the proposals and established the NSD for a trial period through 1974 . Later a new program of activities was approved for the next three-year period. As the activities proved a success, the NSD was given permanent status from January 1st, 1978.

1) For background information, see Stein Rokkan, "National Primary Socio-Economic Data Structures III: Norway", International Social Science Journal 30(3), 1978:621-652; also Stein Kuhnle and Stein Rokkan, "Political Research in Norway 1960-1975", Scandinavian Political Studies 12, 1978:127-156. 

ways:

The NSD differs from most other organizations of this type in three

- it is a federally structured organization with offices at four universities and with close working arrangements with the regional colleges;

- it has built up a wide variety of data resources across all fields of the social sciences: the data holdings comprise surveys as well as large databanks for communes and census tracts, an archive of information about organizations, and a series of computerized files of data on the recruitment and careers of various elite groups;

- it has established close contacts with a wide range of users in the social sciences and in administrative bodies, partly through its regular newsletter (Brukermelding), partly through the annual meeting of representatives of a great majority of research institutes and teaching departments active in the social sciences throughout Norway.

The NSD has its headquarters at the University of Bergen. In addition there are external data secretariats at each of the other universities: 0s1o, Trondheim and Troms $\phi$.

THE DATA

The NSD has so far built up seven basic types of data holdings:

I The first and largest is the database for communes. This database covers statistics for all local units of administration since 1800 and is linked up with a facility for computer cartography (POLYVRT, CALFORM, SYMAP, FIGUR). This is our most widely used facility and is constantly expanded and improved. A great amount of work has been expended on finding effective solutions to the problems posed by changes in boundaries and units. The database offers detailed documentation of these changes and provides the user with a variety of coefficients for recalculating data values whenever changes occur.

II The NSD has set up a cartographic service useful to a number of users. Coordinate matrices for al1 commune boundaries in Norway since 1800 have been computerized. The boundary segments are identified by a time key to allow the production of maps for every year since 1800 . Initially, maps were mostly conformant using cross-hatchings to represent the data values. Later programs have been developed to display information at the centerpoint of every commune. This development makes it possible to display not only multivariate statistics, but also discrete data about the presence or absence of particular infrastructure elements such as airports, harbours, hospitals, schools, factories etc.

III To allow analyses at a lower level of aggregation the INSD has taken steps to organize a set of data at the lowest level of official 
enumeration: the census tract. This data bank contains data from the censuses of $19 \overline{60}$ and 1970 and has proved of great interest to cjty planners, geographers, anthropologists and sociologists.

IV In dealing with survey data it has been our policy to link up response data for comparable questions over time, so we have deliberately declined to serve as a depository for individual studies. The largest file so far developed covers the surveys of the Norwegian Gallup Institute (roughly monthly ones) from 1964 through 1976. Currently, this archive is being updated with data from the Norsk Opinionsinstitutt A.S. (Norwegian 0pinion Institute). A similar linkage is being completed for the electoral surveys carried out by Professor Henry valen and his colleagues since 1957. Some of the most thorough surveys carried out by the Central Bureau of Statistics since 1967 are now at the disposal of academic users under an agreement with the NSD. The NSD has prepared detailed documentation for some of these surveys and reformatted them for use with SPSS to increase their availability.

$\checkmark \quad$ A major effort has been made to develop a systematic databank for eljte groups. The first file to be completed contains biographic information on Members of Parliament since 1814, This archive gives information on father's occupation, education, early career, positions in legislative committees etc. The file has recently been linked with one for roll calls since the establishment of party fronts in the 1870's to allow analyses of interrelations between background factors and legislative behaviour. Similar biographical files are being organized for members of the central administration as well as for graduates from the universities since 1811 .

VI Another file taken over by the NSD is the archive of information about voluntary associations in Norway 1971/1972.

VII The NSD has also got a file of test data for the recruits to the Armed Forces from 1951 to 1968.

In organizing these as well as other data the NSD has emphasized the paramount importance of documentation and data linkage. The NSD does not wish to serve as a pure depository of data. Consequently, data files are rarely incorporated into our holdings unless they can be fully documented and linked up into a system either topically or across time periods.

To make sure that our facilities are used extensively, the NSD has given high priority to educational activities, courses, lectures and teaching packages. Active support has been offered within the programme of the International Social Science Council as one of the cross-national workbooks in the ISSC series has been produced in close cooperation with the NSD. Steps have also been taken to compile a series of specifically Norwegian teaching packages. One of these is based on fiscal-administrative data for communes, another focuses on time-series data for intermediary levels of regional aggregation (fylker). Further packages are based on data from electoral surveys and the file of biographical information on Members of Parliament. 
Up until 1977 NSD was almost exclusively financed by grants from the Social Science division of the Research Council. At that time it was realized that NSD holdings were used extensively by groups other than social scientists and for purposes other than research and teaching. Even more important, some governmental agencies as well as the NSD realized that our data archives carried a huge potential for several kinds of governmental planning and research. This potential was likely to grow not least as a result of increased co-operation with the Central Bureau of Statistics. Consequently, our financing had to be altered in one way or another. Several models were discussed, but in the end the ISD is still being financed on a project basis. A major advantage of this arrangement is that it allows the Research Council and the NSD to set the priorities. At the same time we can also choose the governmental projects that appear to give the greatest benefits to the social sciences in general.

\section{From 1978 to 1987 the basic grant to the NSD increased from about 1} mi17. to $1.4 \mathrm{mi} 11$. Nkr., each year totalling about $8 \%$ of the Research Council allocation to social science projects. If this were to be our total budget, it would restrict our expansion considerably. However, we have been able to obtain supplementary funding elsewhere, including grants from other divisions of the Research Council, the Nordic research councils and various governmental agencies.

The current funding of the NSD allows us to keep a reasonably large group of professionals permanently employed. As of today all full-time staff except the secretaries have a university degree. Our recruitment policy has always been to emphasize social science background with experience in data analys is and programming. Such experience is achieved through the training of recruits as assistants either at the NSD or on large research projects at the universities. The academic background of the staff covers almost the full range of the social sciences: economicz, sos:oicgy, political science, geography, public administration, history and information science. Not only does this provide a good interdisciplinary working group, it also makes it easy to communicate with various research interests. The recruitment policy definitely reflects the tasks that have been assigned priority by the Board of the NSD.

To put it simply, data and documentation are given priority over software development and programming. However, the NSD is seldom involved in primary data collection. In effect, we place great store by establishing good working relations with data collecting agencies in administrative bodies, private firms and research institutes.

Obviously, the most important of these is the Central Bureau of statistics. We now cooperate rather extensively with the Bureau and also exchange services to some extent. This co-operation means that we are able to provide social scientists with virtually all data collected by the Bureau at a very low cost that often amounts to no more than the copying of the magnetic tape. The NSD has also been assigned the responsibility for giving social scientists access to Bureau data that are not completely anonymized, provided that the Bureau receives feedback as to who is given access. Furthemore, the iND is represented on comittees to review census questionnaires and Bureau tables to be publicized using census tata. 
To a certain extent we are developing similar relationships with other governmental agencies supporting data collection tasks.

Currently, we are cooperating with the Ministry of Consumer Affairs on the computerization of a register of representatives in official boards and councils. We do part of the coding and punching as well as the running of simple tables to be used in the official report. Later, these data will be established as an archive and included in the data holdings available to researchers free of charge.

There are several reasons why such excellent and confident relationships can be developed vis-a-vis the governmental agencies. One of the most important reasons seems to be that there has never been any abuse of data by students or researchers. The NSD has also shown the ability to store and document data in a way that permits simple computer runs, map drawings etc. much faster, cheaper and often with better quality compared with other data distributors. Since the holdings of the NSD contain data collected by means of public funds, there is also a strong argument for maximum public usage of these data.

Before leaving our relationship with governmental agencies, we must also mention the effect of privacy legislation on social research. As soon as the privacy law was proposed, the NSD took the initiative to help fulfill the intentions of the law as well as to counteract some of the negative effects experienced in other countries. After lengthy negotiations we are now in the process of implementing a strategy that we believe is advantageous for all parties concerned. First, the NSD has been given a general consession by the Data Inspectorate to archive and store relevant social science data. Second, we have obtained a grant for acting as a 1 iaison between the research community and the Data Inspectorate. It also enables us to set up a secretariat for the Research Council on matters concerning privacy and data collection.

\section{INTERNATIONAL COOPERATION}

On the international side, the NSD has always been cooperating actively with similar organizations in other countries. It was one of the founder members of the International Federation of Data Organizations in 1977 and is active in a Working Group under its auspices for the coordination of local - regional data bases and computer cartography.

Since 1971, information about European archiving efforts has been published regularly in the European Political Data News letter set up by Stein Rokkan under the European Consortium for Political Research and later co-sponsored by the Norwegian Social Science Data Services. The EPD Newsletter has developed a classification scheme for the comparison of the contents of European time-series datasets and has repeatedly advocated actions to co-ordinate developments in this field.

First, NSD and the Norwegian Research Council succeeded in securing the sponsorship of the European Science Foundation for a meeting on "Databases for Regional Analys is" in 1977. 
Second, NSD took steps to develop a proposal for the establishment of a Joint Nordic Database for Regional Time Series during 1977-1979. Funding for a three-year period was granted by the four Nordic Social Science Research Councils, i.e. the Danish, Finnish, Norwegian and Swedish. The project started in January 1979.

Also, at the IFDO meeting on regional data held in Turin in March 1980, the task of coordinating an effort to summarize and structure information for a joint European database was entrusted to NSD. NSD waS asked to complete the matrix or map of available data on the basis of the work started in Turin, to disseminate a report and organize a workshop in which further action can be discussed.

The effort implies the following:

a. to identify organizations and scholars in each nation who are willing to cooperate, and to look for additional researchers and scholars in cases where regional or thematic gaps in the databases have been identified;

b. to establish a common standard for types of variables in these databases;

c. to establish a common standard for documentation of these data;

d. to carry out an effort as far as possible to establish the comparability of these data. This task does not necessarily imply the establishment of formal statistical comparability, but a more substantive kind of theoretical comparability, such as the possibility of using analogous measures for common research projects of analysis of social structures and processes.

NSD concludes from this information-gathering effort that it will be feasible to start the building up of a first version of a Joint European Data Base for Regional Time Series. At this time we have established a network of contacts and compiled information about data matrices and variable lists. A report on the progress of the project has been submitted to the Board of IFDO for further discussion. 